\title{
LULISMO: UMA REVOLUÇÃO PASSIVA OU REFORMA GRADUAL?
}

\author{
Anderson Ferreira da Silva \\ anderexcel@yahoo.com.br
}

\section{Introdução}

Vivemos há mais de 10 anos o Partido dos Trabalhadores (PT) na presidência da República: Lula (de 2003 a 2010) o primeiro presidente brasileiro que não vinha das elites e Dilma (de 2011 até os dias atuais) a primeira mulher presidente do Brasil. O governo de Dilma está sendo um governo de continuidade das políticas feitas por Lula, ou seja, o governo dela não rompeu com seu antecessor, pelo menos até 2014 o lulismo ainda prevaleça.

O que o lulismo tem de diferente dos outros governos? Os pobres e os mais pobres que antes não votavam no PT passaram a votar nele. Segundo Andre Singer houve uma lenta penetração do PT nas classes mais pobres e na região Nordeste do país, já o PSDB desde sua fundação vem tendo eleitores da classe média. Sob a figura do Lula os mais pobres passaram a receber os programas de transferência de renda e assim muitos saíram da extrema pobreza.

O lulismo passou a ser a combinação de desenvolvimentismo econômico (um crescimento do produto interno bruto) aliado aos programas de transferência de renda aos pobres. O temor ao Lula ficou no passado tanto entre os mais pobres como nos mais ricos, o temor que Lula rompesse com o capital não existi mais. O que é esse lulismo que unem ricos e pobres? Será esse um fenômeno único ou um reflexo da teoria do Brasil como um ornitorrinco: uma combinação esdrúxula de setores altamente desenvolvidos, um setor financeiro macrocefálico, mas com pés de barro (ou seja, aquilo que há de mais atrasado sustenta aquilo que há de mais moderno, o atrasado e o moderno convive num mesmo país)? 


\section{Justificativa}

A partir de 2003 tendo uma mudança na conjuntura econômica internacional, a adoção de políticas para reduzir a pobreza (combate à miséria), ativação do mercado interno, sem romper com o capital, esse cenário teria produzido juntamente com a crise do suposto mensalão (deputados teriam recebido dinheiro para votar de acordo com o governo) um realinhamento eleitoral que se firmou em 2006.

Segundo Andre Singer a expressão realinhamento eleitoral foi designada nos Estados Unidos para falar da transformação de clivagens fundamentais do eleitorado que nomeiam um ciclo político longo. Determinadas conversões de blocos de eleitores são capazes de ditar uma agenda de longo prazo. Em 2002, deu inicio a fase prolongada no Brasil (como ocorreu com a eleição de Franklin Roosevelt nos Estados Unidos). Nos Estados Unidos em 1932, assim como no Brasil em 2002, ocorre uma eleição de alternância, forma-se uma nova maioria. Em 2006, Lula se reelege, em função de mudanças governamentais tomadas no $1^{\circ}$ mandato de Lula, a classe média se afasta e os mais pobres ocupam esse lugar. O processo de mudança começou em 2002, mas foi em 2006 que o subproletariado adere ao Lula e a classe média ao PSDB.

Paul Singer no livro "Dominação e desigualdade" (página 22) definem os subproletários como aquela parcela da população que "oferecem sua força de trabalho sem encontrar quem esteja disposto a adquiri-la por um preço que assegure sua reprodução em condições normais" segundo Paul Singer quem pertenceriam a essa classe seriam os "empregados domésticos assalariados de pequenos produtores diretos e trabalhadores destituídos das condições mínimas de participação na luta de classes". Essa classe foi mais beneficiada pelas políticas de transferência de renda adotadas pelo governo Lula.

\section{Objetivos}

Quem são esses que aderem ao lulismo? É essa massa de pobres ou miseráveis (os subproletários) que não conseguiam se auto-organizar, reivindicar. Mas viram iguais a eles (personificado na figura do Lula) que poderiam fazer aquilo que eles não conseguiriam fazer?

O Lulismo seria muito próximo da "revolução passiva" do Gramsci. Carlos Nelson Coutinho define no livro "Gramsci, um estudo sobre seu pensamento político" 
(página 198): "um processo de revolução passiva, ao contrário da revolução popular, realizada de 'baixo', jacobina, implica sempre a presença de dois momentos: o da restauração (na medida em que é uma reação à possibilidade de uma transformação efetiva e radical 'de baixo para cima') e o da renovação (na medida em que muitas demandas populares são assimiladas e postas em prática pelas velhas camadas dominantes)". Lula não rompeu totalmente, ele incorporou muitas demandas populares (acesso maior à universidade, programas de transferência de renda) nos seus dois governos e ainda consegue eleger sua sucessora.

"Ao contrário do que supunha a tradição 'marxista-leninista', o Brasil experimentou um processo de modernização capitalista sem por isso ser obrigado a realizar uma 'revolução democrática-burguesa'ou de 'libertação nacional' segundo o modelo jacobino: o latifúndio pré-capitalista e a dependência em face do imperialismo não se revelaram obstáculos insuperáveis ao complexo desenvolvimento capitalista do País. Por um lado, gradualmente e 'pelo alto', a grande propriedade latifundiária transformou-se em empresa capitalista agrária; e, por outro lado, como a internacionalização do mercado interno, a participação do mercado estrangeiro contribui para reforçar a conversão do Brasil em país industrial moderno, com uma alta taxa de urbanização e uma complexa estrutura social. Ambos os processos foram incrementados pela ação do Estado: ao invés de ser o resultado de movimentos populares, ou seja, de um processo dirigido por uma burguesia revolucionária que arrastasse consigo as massas camponesas e os trabalhadores urbanos, a transformação capitalista teve lugar graças ao acordo entre as frações das classes economicamente dominantes, com a exclusão das forças populares e a utilização permanente dos aparelhos repressivos e de intervenção econômica do Estado. Nesse sentido, todas as opções concretas enfrentadas pelo Brasil, direta ou indiretamente ligadas à transição para o capitalismo (desde a Independência política ao golpe de 1964, passando pela Proclamação da República e pela Revolução de 1930), encontraram uma solução 'pelo alto', ou seja, elitista e antipopular" (Carlos Nelson Coutinho. Gramsci, um estudo sobre seu pensamento político. Página 196)

Temos com o lulismo: os programas de transferência de renda, além da redução da pobreza têm também um novo mercado interno aquecido; pessoas que antes não consumiam nada passaram a consumir isso pode não parecer nada, mas pensem milhões 
de famílias recebendo esses benefícios, movimentando os pequenos e médios comércios, assim gerando empregos, aquecendo a economia, fazendo aumentar o poder aquisitivo, gerando emprego e renda. E ainda as outras medidas de incentivo a consumo como a redução de impostos como IPI, barateando os produtos industrializados. E mais ainda a concessão de bolsas de estudo para estudantes em universidades privadas e o aumento da construção de novas universidades federais.

Mas por outro lado temos um endividamento das pessoas, uma desmobilização das massas, se aquilo que antes era uma demanda das classes populares passa a ser do gabinete do governo, para que as massas vão se mobilizar já que tudo é uma mera medida governamental.

O Lulismo se mostra com seus pontos positivos e negativos já meio esboçados acima, mas a questão que fica para esse projeto: Por que aderiram ao Lulismo?Quem são esses que aderiram ao lulismo?

\section{Cronograma:}

De abril a junho de 2014.

Contraposição contra e favor do lulismo, sugestões de leituras:

Andre Singer. Os sentidos do Lulismo Reforma Gradual e Pacto Conservador. Cia das Letras. 2012

Chico de Oliveira, Ruy Braga e Cibele Rizek (orgs.). Hegemonia às Avessas. Ed. Boitempo. 2010

Chico de Oliveira. Crítica à razão dualista e o Ornitorrinco. Ed Boitempo. 2003.

Braga, Ruy. A política do precariado: do populismo à hegemonia lulista. Ed Boitempo.

Sader, Emir (orgs).10 anos de governos pós-neoliberais no Brasil: Lula e Dilma. Ed Boitempo. 2013

De julho a setembro de 2014.

Origens do Lulismo, sugestões de leituras:

Castel, Robert. As metamorfoses da questão social. Ed. Vozes. 
Gramsci, Antonio. Cadernos do Cárcere.

Carlos Nelson Coutinho. Gramsci, um estudo sobre seu pensamento político.

De outubro a novembro de 2014.

Conceitos de filosofia, sugestões de leituras:

Foucault, Michel. Sujeito e poder.

Agamben, Giorgio. Homo Saccer.

\section{$\underline{1^{a} \text { etapa: Fichamento do livro do André Singer "Os sentidos do }}$}

\section{lulismo"}

Segundo Andre Singer no livro "Os sentidos do Lulismo" é muito difícil definir de maneira exata o que é o lulismo, pois esse fenômeno ainda está em curso. Conservação, mudança, reprodução, superação, decepção e esperança são alguns dos possíveis adjetivos atribuídos feitos pelo autor sobre o lulismo.

O Lula adotou em seu governo como principal medida: a redução da pobreza social e regional por meio do mercado interno, melhorando o assim o padrão de consumo das regiões mais pobres do Brasil, não entrando em conflito com os interesses do capitalismo atual.

O que decretou o nascimento do termo lulismo foi exatamente à relação dos mais pobres com o Lula, como os mais pobres foram beneficiados por programas governamentais que tinham como intuito melhorar as suas condições de vida. Esses mais pobres assim reelegeram Lula em 2006.

O lulismo modificou a sua base social de apoio do PT. O PT na sua fundação era um partido em sua maioria era formado pela classe média, o PT passou ao longo dos anos a penetrar nos movimentos sociais e hoje o PT é formado em sua maioria por pessoas de baixa renda justamente pelos movimentos sociais e pelosa programas de transferência de renda. Houve um aumento do crescimento econômico com redução das desigualdades sociais principalmente com a anexação do subproletariado à situação proletária pelo emprego formal. Pela via ideológica, lulismo se baseia no modelo do Getulio Vargas, aonde ele se coloca como aliado do" povo" e quem não estão do lado do Lula é o "antipovo". 
Andre Singer cita Caio Prado Junior aonde ele coloca que para a nação romper o círculo vicioso do atraso está ligado a existência de uma massa de miseráveis:

“(...) a herança colonial brasileira ainda faz sentir, no essencial, todos ou pelo menos seus principais efeitos. Constituímos ainda, numa perspectiva ampla e geral (...), um aglomerado humano heterogêneo e inorgânico, sem estruturação econômica adequada, e em que as atividades produtivas de grande significação expressão não se acham devidamente entrosadas com as necessidades próprias da massa da população. E como conseqüência desse estado de coisas (...) vai à economia brasileira incidir no círculo a que já nos referimos: os baixos padrões e nível de vida da grande massa da população brasileira não dão margem para atividades produtivas em proporções suficientes para absorverem a força de trabalho disponível, e assegurarem com isso ocupação e recursos adequados àquela população.” (Caio Prado Junior. A revolução brasileira. Páginas 252 e 253)

Segundo Frei Beto, o programa Fome Zero teria criado "comitês gestores" em mais de 2.000 cidades. Esses comitês eram formados por representantes da sociedade social local, que poderiam ser uma fonte de mobilização por baixo para abrir caminho para uma redução acelerada da desigualdade. Com o lançamento do programa Bolsa Família (que incorporou o programa Fome Zero) esses comitês passaram a perder função, pois o cartão do programa era um convênio entre as prefeituras e o governo federal. Trazendo assim uma desmobilização das classes e não permitindo uma autoorganização para a luta política das classes. 